\title{
Compactação de um Latossolo Vermelho Distroférrico com diferentes quantidades e manejos de palha em superfície
}

\author{
Daniel Coelho Rosim (1); Isabella Clerici De Maria (2*); Renato Lemos e Silva (1); Álvaro Pires da Silva (3) \\ (') Programa de Pós-graduação em Agricultura Tropical e Subtropical, IAC. Av. Barão de Itapura, 1481, 13029-970 Campinas (SP), Brasil. \\ (2) Instituto Agronômico (IAC), Av. Barão de Itapura, 1481, 13020-970 Campinas (SP), Brasil. \\ (3) ESALQ/USP, Departamento de Ciência do Solo, Av. Pádua Dias, 11, 13418-260 Piracicaba (SP), Brasil. \\ (*) Autor correspondente: icdmaria@iac.sp.gov.br
}

Recebido: 4/mar./2012; Aceito: 13/out./2012

\section{Resumo}

A compactação do solo em áreas agrícolas manejadas em sistema plantio direto tem sido apontada como um problema enfrentado por produtores, em especial nas áreas com solos argilosos. A compactação é causada principalmente pelo tráfego de máquinas, quando não são respeitadas faixas adequadas de umidade do solo. A palha na superfície do solo, por criar uma barreira física entre o pneu das máquinas e o solo, pode ser um fator de minimização da compactação. Assim, o objetivo do estudo foi avaliar o efeito da palha de milheto em superfície na redução da compactação do solo causada pelo rodado de um trator. O experimento constou de quatro tratamentos de quantidade de palha (sem palha, 5, 10 e $15 \mathrm{Mg}$ ha-1) e três de manejo da palha (em pé, tombada e fragmentada). Após a passagem do trator determinou-se a resistência à penetração, umidade, densidade e porosidade total do solo na área trafegada. A densidade e porosidade total não foram afetadas pela passagem do tráfego. Nos tratamentos com palha, obteve-se maior umidade e, consequentemente, menor resistência. Entre os tratamentos de manejo da palha não houve diferença para umidade e resistência. Para a mesma umidade do solo, maiores quantidades de palha resultaram em menores valores de resistência à penetração, evidenciando menor compactação.

Palavras-chave: plantio direto, resistência do solo, tráfego de máquinas agrícolas.

\section{Soil compaction in a Rhodic hapludox soil as influenced by straw management and quantity on surface}

\begin{abstract}
Soil compaction in areas under no-tillage has been pointed as a problem faced by farmers, particularly in areas with clay soils. Compaction is mainly caused by machinery traffic when the adequate soil moisture is not respected. Straw on the soil surface, by creating a physical barrier between the wheel and the ground may be a factor to minimize compaction. Therefore, the objective of this study was to evaluate the effect of millet straw on soil surface in reducing compaction caused by the tractor wheels. The experiment consisted of four treatments of straw quantity on surface (without straw and 5, 10 and $15 \mathrm{Mg} \mathrm{ha}^{-1}$ ) and three straw managements (standing up, lying down and fragmented). After the tractor passage, penetration resistance, water content, density and total porosity of soil were evaluated on the area where the wheel passed over. Density and porosity were not affected by wheel traffic. Treatments with straw had higher water content and as a result less resistance. There was no significant difference on resistance and soil moisture among straw management treatments. For an equal soil water content, higher densities of straw resulted in lower penetration resistance, which indicates less compaction.
\end{abstract}

Key words: no-tillage, soil resistance, agricultural machinery traffic.

\section{INTRODUÇÃO}

A compactação afeta as propriedades e funções físicas, químicas e biológicas do solo, sendo uma das principais causas da degradaçấo das áreas agrícolas no mundo. Os principais efeitos negativos da compactação são: aumento da resistência mecânica ao crescimento radicular e redução da aeração e da disponibilidade de água no solo com consequente decréscimo da produtividade e da qualidade das culturas e aumento da força requerida para o preparo e semeadura (CAMARgo e Alleoni, 1997; SoAne, 1990). Além dos efeitos sobre o desenvolvimento vegetal, a compactação causa diminuição da infiltração de água no solo, favorecendo o encharcamento temporário, aumentando a enxurrada e favorecendo os processos erosivos (Bertoni e Lombardi Neto, 2008).

Com a introdução do sistema plantio direto (SPD), há aumento na densidade e na resistência à penetração, 
em comparação com os solos preparados, como vem sendo observado por diversos autores (DE MARIa et al., 1999; Draghi et al., 2005; LAMpurlanés e CANTERO-MatínEZ, 2003; Stone e Silveira, 1999; Tormena et al., 2002; 2004). Embora esse efeito não tenha limitado o crescimento das raízes e a produção das culturas em solos bem estruturados, a compactação do solo em superfície é apontada como um dos principais problemas do SPD e pode estimular o abandono do sistema, mesmo que temporariamente.

O papel da matéria orgânica na prevenção da compactação tem sido associado à formação de agregados maiores e mais estáveis nos solos com maiores níveis de material orgânico. BraIdA et al. (2010) observaram redução da compressibilidade em um Nitossolo de textura argilosa com o incremento de carbono orgânico, embora o mesmo efeito não tenha sido observado para Argissolo arenoso. SHAver et al. (2002) observaram que, após 12 anos sob sistema plantio direto, o incremento da produção de resíduos resultou em melhoria nas propriedades físicas do solo, com redução da densidade e aumento na porosidade.

No SPD, a presença de palha na superfície do solo pode criar condiçóes para que parte da energia de compactação produzida pelo trânsito de máquinas e animais seja dissipada antes do contato com o solo. De acordo com SoAne (1990), a matéria orgânica não decomposta acumulada na superfície do solo tem como efeito o aumento da área de contato das rodas e a reduçáo da compactação das camadas superficiais do solo. Trabalhando em dois Latossolos argilosos, Silva et al. (2007) verificaram que o tráfego sobre os resíduos florestais atenuou a compactação nos solos estudados, comparativamente ao solo limpo descoberto. Resultados de Braida et al. (2006), em solos arenoso e argiloso, indicaram que a palha na superfície do solo, durante a realização do ensaio Proctor, dissipa até $30 \%$ da energia de compactação utilizada, com redução da densidade máxima obtida.

Acharya e Sharma (1994); Dao (1996); Ess et al. (1998) e LEÃo et al. (2004) observaram que a cobertura do solo proporcionou diminuição da compactação no solo. No entanto, no trabalho de Gupta et al. (1987), os efeitos da palha não foram significativos na diminuição da compactação do solo causada pelo tráfego.

No presente trabalho, foi avaliado o efeito da quantidade e do manejo da palha na superfície do solo em atributos indicadores de alteração da estrutura de um solo argiloso, após tráfego de um trator, para verificar se a presença da palha pode auxiliar na redução da compactação do solo na adoção de sistema plantio direto.

\section{MATERIAL E MÉTODOS}

O experimento foi realizado em um Latossolo Vermelho Distroférrico (EMBRAPA, 2006) de textura argilosa, cuja caracterização físico-química nas camadas $0,0-0,2 \mathrm{~m}$ e 0,8-1,0 m é apresentada na tabela 1 . O clima da região $\left(22^{\circ} 52^{\prime} 06^{\prime \prime} \mathrm{S}\right.$ $\left.-47^{\circ} 05^{\prime} 27^{\prime \prime} \mathrm{W}\right)$, segundo a classificação de Köppen, é uma transição entre os tipos Cwa e Cfa (Rolim et al., 2007).

Adotou-se o delineamento experimental de blocos ao acaso com parcelas subdivididas e quatro repetiçôes, seguindo os tratamentos: quatro quantidades de palha em superfície $\left(0,5,10\right.$ e $\left.15 \mathrm{Mg} \mathrm{ha}^{-1}\right)$ na parcela e três sistemas de manejo de palha em pé (intacta), deitada e fragmentada, nas subparcelas. A área útil total do experimento foi de $1.536 \mathrm{~m}^{2}$, com parcelas de $32 \mathrm{~m}^{2}(4 \times 8 \mathrm{~m})$ e bordaduras de $3 \mathrm{~m}$ entre as parcelas e $5 \mathrm{~m}$ entre os blocos.

Em 21 de setembro de 2005, a área experimental foi preparada no sistema convencional, com uma aração com arado de aivecas e duas gradagens, a uma profundidade de 0,20 a $0,25 \mathrm{~m}$. A seguir foi feito o plantio do milheto (Pennisetum glaucum, cultivar 'BN-2').

Variou-se a quantidade de sementes plantadas empregando-se 0, 27, 54 e $81 \mathrm{~kg} \mathrm{ha}^{-1}$ de sementes, com intuito de obter diferentes quantidades de palha nas parcelas conforme os tratamentos estabelecidos: 0, 5, 10 e $15 \mathrm{Mg} \mathrm{ha}^{-1}$ de palha (massa seca). Um dia após o preparo do solo foi feita a semeadura do milheto, com $200 \mathrm{~kg} \mathrm{ha}^{-1}$ do adubo NPK 8-28-16. Para essa operação, utilizou-se uma semeadora-adubadora de discos duplos concêntricos, no espaçamento de 0,30 m entrelinhas.

Oitenta dias após a semeadura, foi feita a dessecação química do milheto com $3 \mathrm{~L} \mathrm{ha}^{-1}$ de glyphosate, e avaliada a quantidade de massa seca das parcelas coletando $0,25 \mathrm{~m}^{2}$ da parte aérea das plantas e secando a $60{ }^{\circ} \mathrm{C}$ por 48 horas em estufa de circulação forçada.

A utilização de diferentes quantidades de sementes não foi suficiente para chegar aos quatro tratamentos de quantidade de palha desejados (Figura 1) e houve

Tabela 1. Caracterização físico-química do Latossolo Vermelho Distroférrico, de textura argilosa

\begin{tabular}{lccccc} 
Camada & \multicolumn{5}{c}{ Atributo } \\
\cline { 2 - 6 } & $\begin{array}{c}\text { Argila } \\
(\%)\end{array}$ & $\begin{array}{c}\text { Silte } \\
(\%)\end{array}$ & $\begin{array}{c}\text { Areia Fina } \\
(\%)\end{array}$ & $\begin{array}{c}\text { Areia Grossa } \\
(\%)\end{array}$ & $\begin{array}{c}\text { CTC } \\
\left(\mathbf{m m o l}_{\mathbf{c}} \mathbf{~ d m}^{-3}\right)\end{array}$ \\
\hline $0,0-0,2$ & 60 & 9 & 13 & 18 & 84 \\
$0,8-1,0$ & 68 & 7 & 11 & 15 & 49
\end{tabular}

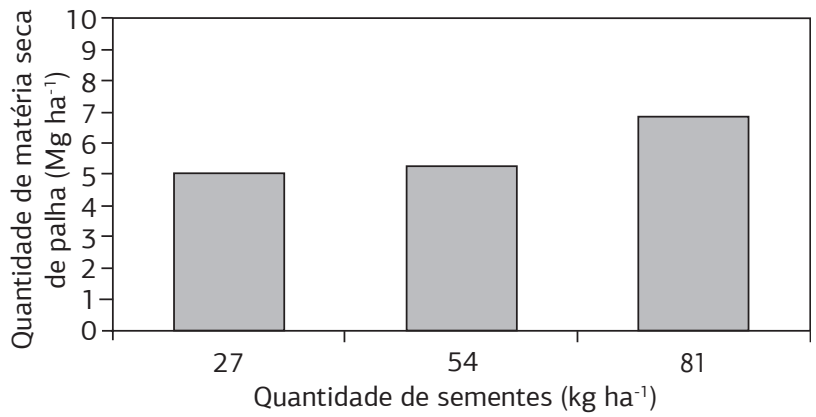

Figura 1. Quantidade de massa seca (palha) produzida pelo milheto (Pennisetum glaucum) em função da quantidade de sementes utilizadas em espaçamento de 0,3 m entre linhas na semeadura. 
necessidade de ajuste, acrescentando ou retirando palha das parcelas. $\mathrm{O}$ ajuste nas parcelas com a palha em pé foi feito da mesma forma que nas parcelas com palha deitada, acrescentando ou retirando plantas inteiras.

Os tratamentos de manejo da palha (palha em pé, deitada e fragmentada) foram feitos manualmente, sendo a palha em pé não manejada, deixando-se a planta secar na forma natural de crescimento; a palha deitada obtida tombando-se a palha por pisoteio; a palha fragmentada obtida cortando-se o milheto com foice em duas alturas, $2 / 3$ e $1 / 3$ da altura total da planta, resultando em fragmentos de aproximadamente $0,40 \mathrm{~m}$ de comprimento.

Após $47,1 \mathrm{~mm}$ de chuvas, três dias após o manejo da palha, com o solo na consistência plástica, um trator marca Massey Ferguson, modelo 292, com peso total de 5,65 Mg trafegou sobre as parcelas, na velocidade de $6 \mathrm{~km} \mathrm{~h}^{-1}$, simulando uma operação de manejo (dessecação de plantas com herbicidas) para implantação de uma cultura no SPD (Figura 2).

Todas as avaliaçóes foram feitas na área trafegada pelo rodado do trator, previamente demarcada por estacas. As avaliações de resistência à penetração $(\mathrm{MPa})$, umidade gravimétrica $\left(\mathrm{g} \mathrm{g}^{-1}\right)$ foram feitas nas camadas $0,0-0,1$; $0,1-0,2$ e $0,2-0,3 \mathrm{~m}$ no $1^{\circ}, 6^{\circ}$ e $8^{\circ}$ dias após a passagem do trator. Avaliaçóes de densidade $\left(\mathrm{Mg} \mathrm{m}^{-3}\right)$ e porosidade $\left(\mathrm{m}^{3} \mathrm{~m}^{-3}\right)$ foram feitas nas mesmas profundidades no $13 .^{\circ}$ dia após a passagem do trator.

As avaliaçôes de umidade (Ug), densidade (Ds) e porosidade total (PT) seguiram CAMARGO et al. (1986) e a resistência à penetração $(\mathrm{RP})$ foi medida até $0,3 \mathrm{~m}$ de profundidade, com penetrômetro manual eletrônico, modelo PNT-2000, marca DLG. O equipamento com haste de 0,6 m de comprimento e ponta cônica com base de $0,068 \mathrm{~m}^{2}$ e ângulo de $30^{\circ}$, foi programado para realizar leituras a cada $0,1 \mathrm{~m}$ em um tempo de 10 segundos. Foram feitas cinco avaliaçôes, tomando-se a média como o valor da RP da parcela.
Os dados foram submetidos à análise de variância e testes de comparaçáo de média pelo teste de Tukey a 5\%, utilizando-se o programa SISVAR 4.6 (FERREIRA, 2003).

Por motivo de influência da Ug na RP do solo, os dados de RP foram corrigidos para a mesma Ug, para avaliar os efeitos dos tratamentos na RP independente da umidade, na camada $0,0-0,2 \mathrm{~m}$, onde houve maior variação da $\mathrm{Ug}$, utilizando procedimento proposto por BussCHER et al. (1997).

\section{RESULTADOS E DISCUSSÃO}

Não se observaram interaçôes significativas entre as quantidades de palha e o manejo da palha, em nenhum dos atributos físicos do solo avaliados. Desta forma, serão apresentados e discutidos os valores médios obtidos dos atributos densidade (Ds), porosidade total (PT), resistência à penetração $(\mathrm{RP})$ e umidade gravimétrica $(\mathrm{Ug})$ para cada tratamento separadamente.

Tanto nos tratamentos de quantidade de palha quanto nos tratamentos de manejo da palha não houve diferenças significativas para os parâmetros Ds e PT (Tabela 2), exceto na camada $0,0-0,1 \mathrm{~m}$, onde o manejo com palha em pé, com menor Ds, diferiu significativamente do manejo com palha tombada, com maior Ds. A camada superficial recebe maior pressão do trafego, como demonstraram Cavalieri et al. (2009), estudando efeito do pressão exercida por trator e semeadora na densidade e resistência à penetração do solo.

Apenas uma passagem do trator sobre as parcelas pode não ter sido suficiente para gerar alteraçôes significativas na Ds e PT do solo. STRECK et al. (2004) observaram aumento da Ds e redução da PT até $0,3 \mathrm{~m}$ após quatro passagens de uma máquina com massa de $10 \mathrm{Mg}$ sobre o solo, mas com duas passagens da máquina, as médias foram estatisticamente iguais às da testemunha sem compactação adicional até $0,15 \mathrm{~m}$ de profundidade. Gupta
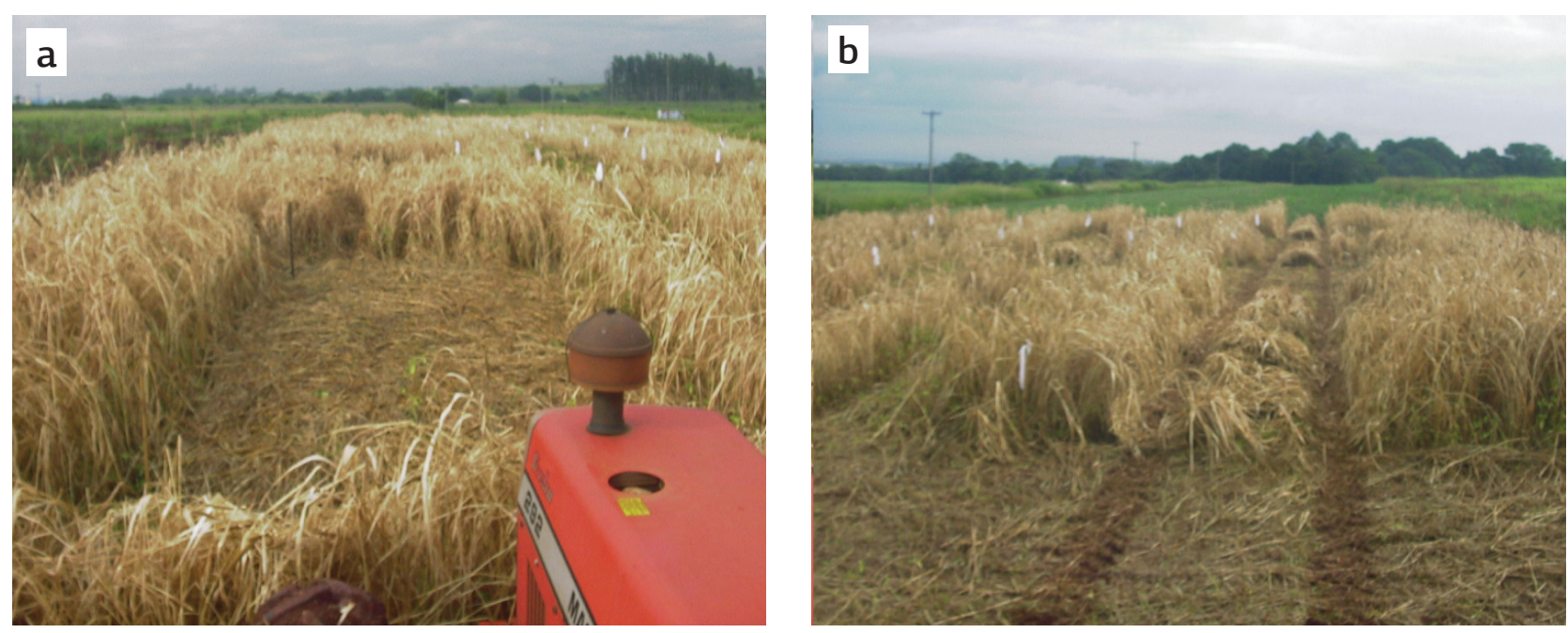

Figura 2. Tráfego sobre a área experimental: (a) Entrada do trator nas parcelas; (b) Rastro do trator nas parcelas. 
et al. (1987), estudando o efeito de resíduos de milho na superfície do solo, também não observaram diferença significativa na densidade e atribuíram essa falta de efeito à variabilidade do solo. Aumentos nos valores de Ds e diminuição da PT são, em geral, observados na camada superficial, apenas após três ou quatro anos de implantação do SPD (Stone e Silveira, 2001).

Os valores médios de resistência à penetração (RP) e umidade $(\mathrm{Ug})$ nos tratamentos um dia após a passagem do trator sobre as parcelas, ocasiáo em que a umidade do solo estava próxima à capacidade de campo, são apresentados na tabela 3 . Na camada $0,0-0,1 \mathrm{~m}$ foram observadas diferenças significativas para valores de $\mathrm{RP}$ entre os manejos de palha, com o manejo com palha em pé resultando em maiores valores de RP, embora esse tratamento tenha apresentado o menor valor de Ds. As diferenças significativas obtidas nessa camada de $0-0,10 \mathrm{~m}$ e no maior nível de umidade do solo indicam dificuldade de determinação da RP em solo muito argiloso, com valores elevados de umidade e com baixa densidade em função da plasticidade e pegajosidade do solo e das irregularidades da superfície no solo. Os valores médios de RP e Ug obtidos no $6 .^{\circ}$ e $8 .^{\circ}$ dias após a passagem do trator são relacionados nas tabelas 4 e 5 . Nota-se que no manejo da palha, com a redução da umidade, não houve diferença significativa em nenhuma das profundidades avaliadas. De forma geral, conclui-se que o manejo da palha não influenciou os parâmetros de estrutura e de umidade do solo avaliados, visto que o tombamento ou a fragmentaçáo da palha exigem tráfego adicional sobre a área, podendo resultar em aumento de densidade na superfície.

Para os tratamentos com diferentes quantidades de palha, no primeiro dia após a passagem do trator, houve diferença significativa entre as médias de RP e Ug na camada $0,0-0,1 \mathrm{~m}$, mas nas camadas $0,1-0,2$ e $0,2-0,3 \mathrm{~m}$, as médias de RP e Ug foram estatisticamente iguais (Tabela 3). Esses resultados indicam que o efeito do tráfego do trator de 5,65 Mg na RP do solo ocorreu apenas em superfície. Tormena e Roloff (1996) e Cavalieri et al. (2009) obtiveram efeito do tráfego de trator e colheitadeira até $0,2 \mathrm{~m}$ de profundidade. Os valores de Ug, nessa camada superficial, foram maiores quanto maior a quantidade de palha. Já para a RP a quantidade de $15 \mathrm{Mg} \mathrm{ha}^{-1}$ de palha na superfície e o tratamento sem palha foram estatisticamente iguais. A quantidade $10 \mathrm{Mg} \mathrm{ha}^{-1}$ de palha proporcionou o menor valor médio enquanto $5 \mathrm{Mg} \mathrm{ha}^{-1}$ de palha, o maior valor de RP. Essas diferenças observadas na RP na superfície no primeiro dia podem ter sido decorrentes da determinaçáo da resistência em elevada umidade do solo, como citado anteriormente.

Nas determinaçóes seguintes (Tabelas 4 e 5), os tratamentos com mais palha proporcionaram maiores valores

Tabela 2. Valores médios de densidade e porosidade total do solo no rastro do rodado em função dos tratamentos de quantidade e de manejo da palha em três profundidades, 13 dias após a passagem do trator na área

\begin{tabular}{|c|c|c|c|c|c|c|}
\hline \multirow{2}{*}{ Profundidade (m) } & \multicolumn{3}{|c|}{ Densidade $\left(\mathrm{Mg} \mathrm{m}^{-3}\right)$} & \multicolumn{3}{|c|}{ Porosidade $\left(\mathrm{m}^{3} \mathrm{~m}^{-3}\right)$} \\
\hline & $0,0-0,1$ & $0,1-0,2$ & $0,2-0,3$ & $0,0-0,1$ & $0,1-0,2$ & $0,2-0,3$ \\
\hline \multicolumn{7}{|l|}{ Quantidade de palha } \\
\hline Sem palha & $1,28 \mathrm{a}$ & $1,36 \mathrm{a}$ & $1,35 \mathrm{a}$ & $0,573 a$ & $0,562 \mathrm{a}$ & $0,539 a$ \\
\hline $5 \mathrm{Mg} \mathrm{ha}^{-1}$ & $1,29 \mathrm{a}$ & $1,33 \mathrm{a}$ & $1,32 \mathrm{a}$ & $0,581 \mathrm{a}$ & $0,566 \mathrm{a}$ & $0,538 \mathrm{a}$ \\
\hline $10 \mathrm{Mg} \mathrm{ha}^{-1}$ & $1,36 \mathrm{a}$ & $1,35 \mathrm{a}$ & $1,32 \mathrm{a}$ & $0,574 \mathrm{a}$ & $0,553 \mathrm{a}$ & $0,541 \mathrm{a}$ \\
\hline $15 \mathrm{Mg} \mathrm{ha}^{-1}$ & $1,31 \mathrm{a}$ & $1,34 \mathrm{a}$ & $1,33 \mathrm{a}$ & $0,584 \mathrm{a}$ & $0,567 \mathrm{a}$ & $0,553 \mathrm{a}$ \\
\hline \multicolumn{7}{|l|}{ Manejo de palha } \\
\hline Palha em pé & $1,28 \mathrm{a}$ & $1,35 \mathrm{a}$ & $1,32 \mathrm{a}$ & $0,580 \mathrm{a}$ & $0,559 \mathrm{a}$ & $0,539 a$ \\
\hline Palha tombada & $1,33 \mathrm{~b}$ & $1,34 \mathrm{a}$ & $1,34 \mathrm{a}$ & $0,578 \mathrm{a}$ & $0,562 \mathrm{a}$ & $0,541 \mathrm{a}$ \\
\hline Palha fragmentada & $1,32 a b$ & $1,34 \mathrm{a}$ & $1,33 \mathrm{a}$ & $0,575 a$ & $0,564 \mathrm{a}$ & $0,548 \mathrm{a}$ \\
\hline
\end{tabular}

Médias nas colunas seguidas de mesma letra não diferem pelo teste Tukey $(\mathrm{p}<0,05)$.

Tabela 3. Valores médios de resistência à penetração e umidade do solo determinados no rastro do rodado, em função dos tratamentos de quantidade e de manejo da palha, um dia após a passagem do trator, nas três profundidades avaliadas

\begin{tabular}{|c|c|c|c|c|c|c|}
\hline \multirow{2}{*}{ Profundidade (m) } & \multicolumn{3}{|c|}{ Resistência (MPa) } & \multicolumn{3}{|c|}{ Umidade $\left(\mathbf{g ~ g}^{-1}\right)$} \\
\hline & $0,0-0,1$ & $0,1-0,2$ & $0,2-0,3$ & $0,0-0,1$ & $0,1-0,2$ & $0,2-0,3$ \\
\hline \multicolumn{7}{|l|}{ Quantidade de palha } \\
\hline Sem palha & $0,41 a b$ & $0,72 \mathrm{a}$ & $1,57 \mathrm{a}$ & $0,26 \mathrm{a}$ & $0,27 \mathrm{a}$ & $0,26 a$ \\
\hline $5 \mathrm{Mg} \mathrm{ha}^{-1}$ & $0,51 \mathrm{~b}$ & $0,86 a$ & $1,63 a$ & $0,27 a b$ & $0,28 a$ & $0,27 a$ \\
\hline $10 \mathrm{Mg} \mathrm{ha}^{-1}$ & $0,35 a$ & $0,72 \mathrm{a}$ & $1,37 \mathrm{a}$ & $0,28 \mathrm{~b}$ & $0,28 \mathrm{a}$ & $0,27 a$ \\
\hline $15 \mathrm{Mg} \mathrm{ha}^{-1}$ & $0,39 a b$ & $0,57 \mathrm{a}$ & $1,39 \mathrm{a}$ & $0,28 b$ & $0,28 \mathrm{a}$ & $0,27 a$ \\
\hline \multicolumn{7}{|l|}{ Manejo de palha } \\
\hline Palha em pé & $0,49 b$ & $0,77 \mathrm{a}$ & $1,54 \mathrm{a}$ & $0,28 \mathrm{a}$ & $0,28 \mathrm{a}$ & $0,27 a$ \\
\hline Palha tombada & $0,37 \mathrm{a}$ & $0,69 \mathrm{a}$ & $1,41 \mathrm{a}$ & $0,27 \mathrm{a}$ & $0,28 \mathrm{a}$ & $0,27 a$ \\
\hline Palha fragmentada & $0,39 a$ & $0,70 \mathrm{a}$ & $1,52 \mathrm{a}$ & $0,27 \mathrm{a}$ & $0,28 \mathrm{a}$ & $0,26 a$ \\
\hline
\end{tabular}

Médias nas colunas seguidas de mesma letra não diferem pelo teste Tukey $(\mathrm{p}<0,05)$. 
de Ug e, de forma geral, valores crescentes com o aumento da profundidade. Esses resultados concordam com os de diversos autores, como Ess et al. (1998), quando afirmam que os resíduos de plantas que permanecem na superfície mantêm a umidade do solo no decorrer do tempo.

Quando há alteraçáo da umidade do solo devido à chuva, irrigação, evapotranspiração e drenagem, a resistência à penetração do solo é alterada (EHLers et al., 1983). Assim, se a palha ajuda a manter a umidade do solo, é esperado que nos tratamentos com palha, cuja $\mathrm{Ug}$ é maior, os valores de RP sejam menores.

No $6 .^{\circ}$ dia e no $8 .^{\circ}$ dias após a passagem do trator, a palha em superfície reduziu os valores de RP e os efeitos foram significativos com o aumento da quantidade de palha. $\mathrm{O}$ tratamento sem palha resultou em valores médios de RP superiores aos considerados críticos ao crescimento radicular na camada $0,0-0,1$ e $0,2-0,3 \mathrm{~m}$ no $6 .^{\circ}$ dia, e na camada $0,0-0,1 \mathrm{~m}$ no $8 .^{\circ} \mathrm{dia}$. Nos tratamentos com palha, valores críticos foram atingidos na camada $0,2-0,3 \mathrm{~m}$ com $5 \mathrm{Mg} \mathrm{ha}^{-1}$ de palha no $6 .^{\circ}$ e no $8 .^{\circ}$ dias com 5 e $10 \mathrm{Mg} \mathrm{ha}^{-1}$. Considerou-se como crítico o valor de resistência à penetração de 2,0 MPa (TAYlor e Burnett, 1964), que vem sendo adotado por diversos autores (Beutler e Centurion, 2003; Ribon et al., 2003; Silva et al., 1994; Tormena e Roloff, 1996; Tormena et al., 1998).
Com umidade mais elevada, os tratamentos com palha resultaram significativamente nos menores valores de RP (Tabelas 4 e 5). Esse fato pode ser um dos motivos que levam produtores e pesquisadores a acreditar na capacidade do SPD em reduzir a compactação no solo. Como a palha em superfície modificou significativamente os valores de Ug no tempo, principalmente na camada 0,0-0,2 m, o efeito dos tratamentos sobre a compactação do solo pode ter sido encoberto, pois existe correlação negativa $(\mathrm{r}=-0,76)$ entre os atributos RP e Ug (Figura 3).

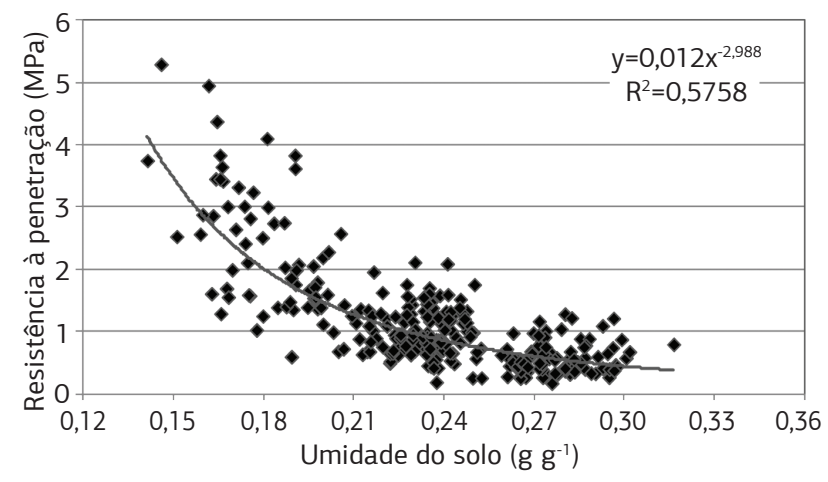

Figura 3. Correlação entre resistência e umidade do solo na camada $0,0-0,2 \mathrm{~m}$.

Tabela 4. Valores médios de resistência à penetração e umidade do solo determinados no rastro do rodado, em função dos tratamentos de quantidade e de manejo da palha, seis dias após a passagem do trator, nas três profundidades avaliadas

\begin{tabular}{|c|c|c|c|c|c|c|}
\hline \multirow{2}{*}{ Profundidade (m) } & \multicolumn{3}{|c|}{ Resistência (MPa) } & \multicolumn{3}{|c|}{ Umidade $\left(\mathbf{g ~ g}^{-1}\right)$} \\
\hline & $0,0-0,1$ & $0,1-0,2$ & $0,2-0,3$ & $0,0-0,1$ & $0,1-0,2$ & $0,2-0,3$ \\
\hline \multicolumn{7}{|l|}{ Quantidade de palha } \\
\hline Sem palha & $2,99 \mathrm{c}$ & $1,75 b$ & $2,34 \mathrm{bc}$ & $0,17 \mathrm{a}$ & $0,19 a$ & $0,21 \mathrm{a}$ \\
\hline $5 \mathrm{Mg} \mathrm{ha}^{-1}$ & $1,10 \mathrm{~b}$ & $1,48 a b$ & $2,37 \mathrm{c}$ & $0,21 b$ & $0,23 \mathrm{~b}$ & $0,23 b$ \\
\hline $10 \mathrm{Mg} \mathrm{ha}^{-1}$ & $0,73 \mathrm{a}$ & $1,16 \mathrm{a}$ & $1,97 a b$ & $0,24 c$ & $0,24 c$ & $0,24 b$ \\
\hline $15 \mathrm{Mg} \mathrm{ha}^{-1}$ & $0,69 a$ & $1,20 \mathrm{a}$ & $1,90 \mathrm{a}$ & $0,24 c$ & $0,24 \mathrm{bc}$ & $0,23 b$ \\
\hline \multicolumn{7}{|l|}{ Manejo de palha } \\
\hline Palha em pé & $1,32 \mathrm{a}$ & $1,40 \mathrm{a}$ & $2,09 \mathrm{a}$ & $0,21 \mathrm{a}$ & $0,23 a$ & $0,23 a$ \\
\hline Palha tombada & $1,39 \mathrm{a}$ & $1,44 \mathrm{a}$ & $2,22 \mathrm{a}$ & $0,21 \mathrm{a}$ & $0,23 a$ & $0,23 a$ \\
\hline Palha fragmentada & $1,40 \mathrm{a}$ & $1,35 \mathrm{a}$ & $2,12 \mathrm{a}$ & $0,21 \mathrm{a}$ & $0,23 a$ & $0,23 a$ \\
\hline
\end{tabular}

Médias nas colunas seguidas de mesma letra não diferem pelo teste Tukey $(\mathrm{p}<0,05)$.

Tabela 5. Valores médios de resistência à penetração e umidade do solo determinados no rastro do rodado, em função dos tratamentos de quantidade e de manejo da palha, oito dias após a passagem do trator, nas três profundidades avaliadas

\begin{tabular}{|c|c|c|c|c|c|c|}
\hline \multirow{2}{*}{ Profundidade (m) } & \multicolumn{3}{|c|}{ Resistência (MPa) } & \multicolumn{3}{|c|}{ Umidade $\left(\mathbf{g ~ g}^{-1}\right)$} \\
\hline & $0,0-0,1$ & $0,1-0,2$ & $0,2-0,3$ & $0,0-0,1$ & $0,1-0,2$ & $0,2-0,3$ \\
\hline \multicolumn{7}{|l|}{ Quantidade de palha } \\
\hline Sem palha & $3,74 \mathrm{c}$ & $1,89 \mathrm{~b}$ & $1,97 \mathrm{a}$ & $0,17 \mathrm{a}$ & $0,19 \mathrm{a}$ & $0,21 \mathrm{a}$ \\
\hline $5 \mathrm{Mg} \mathrm{ha}^{-1}$ & $1,62 b$ & $1,46 a b$ & $2,01 \mathrm{a}$ & $0,19 a$ & $0,22 \mathrm{~b}$ & $0,23 b$ \\
\hline $10 \mathrm{Mg} \mathrm{ha}^{-1}$ & $0,81 \mathrm{a}$ & $1,12 \mathrm{a}$ & $2,00 \mathrm{a}$ & $0,22 b$ & $0,24 b$ & $0,23 b$ \\
\hline $15 \mathrm{Mg} \mathrm{ha}^{-1}$ & $0,66 \mathrm{a}$ & $1,09 \mathrm{a}$ & $1,80 \mathrm{a}$ & $0,23 b$ & $0,24 b$ & $0,23 b$ \\
\hline \multicolumn{7}{|l|}{ Manejo de palha } \\
\hline Palha em pé & $1,58 \mathrm{a}$ & $1,36 \mathrm{a}$ & $1,94 \mathrm{a}$ & $0,20 \mathrm{a}$ & $0,22 \mathrm{a}$ & $0,22 \mathrm{a}$ \\
\hline Palha tombada & $1,66 \mathrm{a}$ & $1,40 \mathrm{a}$ & $1,90 \mathrm{a}$ & $0,20 \mathrm{a}$ & $0,22 \mathrm{a}$ & $0,22 \mathrm{a}$ \\
\hline Palha fragmentada & $1,88 \mathrm{a}$ & $1,42 \mathrm{a}$ & 1,99 a & $0,21 \mathrm{a}$ & $0,22 \mathrm{a}$ & 0,23 a \\
\hline
\end{tabular}

Médias nas colunas seguidas de mesma letra năo diferem pelo teste Tukey $(\mathrm{p}<0,05)$. 
Fazendo a correção dos valores de RP para a mesma Ug, de acordo Busscher et al. (1997), pode-se isolar o efeito da variação da umidade do solo nos valores de RP obtidos (Figura 4). Observa-se que, com a diminuição da umidade do solo nos dias seguintes à passagem do trator, houve aumento da RP no tratamento sem palha, nas camadas de $0,0-0,1$ e $0,1-0,2 \mathrm{~m}$, chegando a valores superiores a 2,0 MPa.

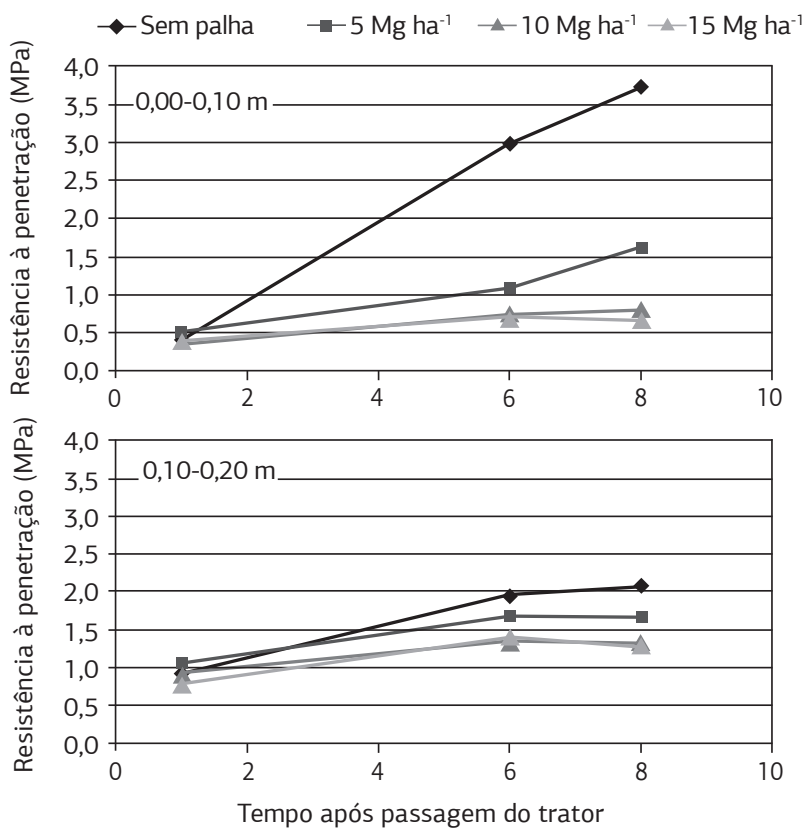

Figura 4. Variação no tempo da resistência à penetração corrigida para a umidade de $0,15 \mathrm{~g} \mathrm{~g}^{-1}$ na camada $0,0-0,1 \mathrm{~m}$ e na camada $0,1-0,2 \mathrm{~m}$

Após a correção dos valores RP para o mesmo valor de umidade, as diferenças entre os tratamentos e os dias de amostragem após a passagem do trator foram mantidas e houve maior aumento da RP no tratamento sem palha. O processo de secagem do solo que contribui para a acomodação, ou aumento da Ds do solo com o tempo, pode ter sido também maior no tratamento sem palha; por esse motivo, as diferenças se ampliam ao tempo mesmo com os valores de resistência corrigidos. O procedimento utilizado para corrigir a umidade tem sido pouco utilizado e há poucas referências para comparação de resultados. Tormena e Roloff (1996), a partir do mesmo procedimento, utilizaram o índice de cone medido com um penetrômetro e o conteúdo de água no solo, em peso, para ajustar os valores do índice de cone em função da diferença entre a umidade do solo no momento da amostragem e um valor padrão adotado, sendo esse valor a média de todos os valores da umidade do solo.

Estudos sobre a dinâmica da resistência à penetração em função da umidade do solo, da quantidade de palha e do tempo sáo ainda necessários para elucidar e ampliar o conhecimento sobre o processo de compactação do solo.

\section{CONCLUSÃO}

A palha em superfície reduziu a resistência à penetração e aumentou a umidade do solo. No entanto, os tipos de manejo de palha náo proporcionaram alteraçóes significativas nos valores de resistência e umidade. Maiores quantidades de palha geraram menores valores de resistência à penetração após correçâo dos valores para a mesma umidade, evidenciando o efeito da palha em superfície na redução da compactação.

\section{AGRADECIMENTOS}

À CAPES, pela concessão da bolsa de mestrado ao primeiro autor, à FAPESP, pela concessão da bolsa de iniciação científica e de mestrado ao terceiro autor, e ao CNPq, pela concessão da Bolsa de Produtividade em Pesquisa ao segundo autor.

\section{REFERÊNCIAS}

ACHARYA, C.L.; SHARMA, P.D. Tillage and mulch effects on soil physical environment, root growth, nutrient uptake and yield of maize and wheat on an Alfisol in north-west India. Soil and Tillage Research, v.32, p.291-302, 1994.

BERTONI, J.; LOMBARDI NETO, F. Conservação do solo. 6.ed. São Paulo: Ícone, 2008. 355p.

BEUTLER, A.N.; CENTURION, J.F. Efeito do conteúdo de água e da compactação do solo na produção de soja. Pesquisa Agropecuária Brasileira, v.38, p.849-856, 2003.

BRAIDA, J.A.; REICHERT, J.M.; REINERT, D.J.; VEIGA, M. Teor de carbono orgânico e a susceptibilidade à compactação de um Nitossolo e um Argissolo. Revista Brasileira de Engenharia Agrícola e Ambiental, v.14, p.131-139, 2010.

BRAIDA, J.A.; REICHERT, J.M.; VEIGA, M.; REINERT, D.J. Resíduos vegetais na superfície e carbono orgânico do solo e suas relações com a densidade máxima obtida no ensaio de proctor. Revista Brasileira de Ciência do Solo, v.30, p.605-614, 2006.

BUSSCHER, W.J.; BAUER, P.J.; CAMP, C.R.; SOJKA, R.E. Correction of cone index for soil water content differences in a coastal plain soil. Soil and Tillage Research, v.43, p.205-217, 1997.

CAMARGO, O.A.; ALLEONI, L.R.F. Compactação do solo e o desenvolvimento das plantas. 1.ed. Piracicaba: Esalq, 1997. 132p.

CAMARGO, O.A.; MONIZ, A.C.; JORGE, J.A.; VALADARES, J.M.A.S. Métodos de análise química, mineralógica e física de solos do Instituto Agronômico de Campinas. Campinas: Instituto Agronômico, 1986. 97p. (Boletim Técnico, 106)

CAVALIERI, K.M.V.; SILVA, A.P.; ARVIDSSON, J.; TORMENA, C.A. Influência da carga mecânica de máquina sobre propriedades físicas de um Cambissolo háplico. Revista Brasileira de Ciência do Solo, v.33, p.477-485, 2009. 
DAO, T.H. Tillage system and crop residue effects on surface compaction of a Paleustoll. Agronomy Journal, v.88, p.141-148, 1996.

DE MARIA, I.C.; CASTRO, O.M.; SOUZA DIAS, H. Atributos físicos do solo e crescimento radicular de soja em Latossolo Roxo sob diferentes métodos de preparo do solo. Revista Brasileira de Ciência do Solo, v.23, p.703-709, 1999.

DRAGHI, L.M.; BOTTA,G.F.; BALBUENA, R.H.; CLAVERIE J.A.; ROSATTO, H. Diferencias de las condiciones mecánicas de un suelo arcilloso sometido a diferentes sistemas de labranza. Revista Brasileira de Engenharia Agrícola e Ambiental, v.9, p.120124, 2005.

EHLERS, W.W.; KÖPKE, F.; HESSE, F.; BÖHM, W. Penetration resistance and root growth of oats in tilled and untilled loess soil. Soil and Tillage Research, v.3, p.261-275, 1983.

EMBRAPA - Empresa Brasileira de Pesquisa Agropecuária - Centro Nacional de Pesquisa de Solos. Sistema Brasileiro de Classificação de Solos. 2.ed. Rio de Janeiro: Embrapa Solos, 2006. 306p.

ESS, D.R.; VAUGHAN, D.H.; PERUMPRAL, J.V. Crop residues and root effects on soil compaction. Transactions of the American Engineering Society of Agricultural Engineers, v.41, p.1271-1275, 1998.

FERREIRA, D.F. Software Sisvar: versão 4.6 (Build 63). Lavras: DEX/UFLA, 2003.

GUPTA, S.C.; SCHNEIDER, E.C; LARSON, W.E.; HADAS, A. Influence of corn residue on compression and compaction behavior of soils. Soil Science Society of America Journal, v.51, p.207-212, 1987.

LAMPURLANÉS, J.; CANTERO-MARTÍNEZ, C. Soil bulk density and penetration resistance under different tillage and crop management systems and their relationship with barley root growth. Agronomy Journal, v.95, p.526-536, 2003.

LEÃO, T.P.; SILVA, A.P.; MACEDO, M.C.; IMHOFF, S.; EUCLIDES, V.P.B. Intervalo hídrico ótimo na avaliação de sistemas de pastejo contínuo e rotacionado. Revista Brasileira de Ciência do Solo, v.28, p.415-423, 2004.

RIBON, A.A.; CENTURION, J.F.; CENTURION, M.A.P.C.; PEREIRA, G.T. Densidade e resistência à penetração de solos cultivados com seringueira sob diferentes manejos. Acta Scientiarum: Agronomy, v.25, p.13-17, 2003.

ROLIM, G.S; CAMARGO, M.B.P; LANIA, D.G; MORAES, J.F. Classificação climática de Köppen e de Thornthwaite e sua aplicabilidade na determinação de zonas agroclimáticas para o Estado de São Paulo. Bragantia, v.66, p.711-720, 2007.
SHAVER, T.M.; PETERSON, G.A.; AHUJA, L.R.; WESTFALL, D.G.; SHERROD, L.A.; DUNN, G. Surface soil physical properties after twelve years of dryland no-till management. Soil Science Society of America Journal, v.66, p.1296-1303, 2002.

SILVA, A.P.; KAY, B.D.; PERFECT, E. Characterization of the least limiting water range of soils. Soil Science Society of America Journal, v.58, p.1775-1781, 1994.

SILVA, A.R.; DIAS JUNIOR, M. de S.; LEITE, F.P. Camada de resíduos florestais e pressão de preconsolidaçáo de dois latossolos. Pesquisa Agropecuária Brasileira, v.42, p.89-93, 2007.

SOANE, B.D. The role of organic matter in soil compactibility: a review of some practical aspects. Soil and Tillage Research, v.16, p.179-201, 1990.

STONE, L.F.; SILVEIRA, P.M. Efeitos do sistema de preparo e da rotação de culturas na porosidade e densidade do solo. Revista Brasileira de Ciência do Solo, v.25, p.395-401, 2001.

STONE, L.F.; SILVEIRA, P.M. Efeitos do sistema de preparo na compactação do solo, disponibilidade hídrica e comportamento do feijoeiro. Pesquisa Agropecuária Brasileira, v.34, p.83-91, 1999.

STRECK, C.A.; REINERT, D.J.; REICHERT, J.M.; KAISER, D.R. Modificaçôes em propriedades físicas com a compactação do solo causada pelo tráfego induzido de um trator em plantio direto. Ciência Rural, v.34, p.755-760, 2004.

TAYLOR, H.M.; BURNETT, E. Influence of soil strength on the root-growth habits of plants. Soil Science Society of America Journal, v.98, p.174-180, 1964.

TORMENA, C.A.; BARBOSA, M.C.; COSTA, A.C.S.; GONÇALVES, A.C.A. Densidade, porosidade e resistência à penetração em Latossolo cultivado sob diferentes sistemas de preparo do solo. Scientia Agricola, v.59, p.795-801, 2002.

TORMENA, C.A.; ROLOFF, G. Dinâmica da resistência à penetração de um solo sob plantio direto. Revista Brasileira de Ciência do Solo, v.20, p.333-339, 1996.

TORMENA, C.A.; SILVA, A.P.; LIBARDI, P.L. Caracterização do intervalo hídrico ótimo de um Latossolo Roxo sob plantio direto. Revista Brasileira de Ciência do Solo, v.22, p.573-581, 1998.

TORMENA, C.A.; VIDIGAL FILHO, P.S.; GONÇALVES, A.C.A.; ARAÚJO, M.A.; PINTRO, J.C. Influência de diferentes sistemas de preparo do solo nas propriedades físicas de um Latossolo Vermelho distrófico. Revista Brasileira de Engenharia Agrícola e Ambiental, v.8, p.65-71, 2004. 